\title{
PERANAN PENYULUH DALAM MENYUKSESKAN PROGRAM KELUARGA BERENCANA
}

\author{
Rizky Andana Pohan', Zainun², Abdul Karim Batubara ${ }^{3}$ \\ Institut Agama Islam Negeri Langsa ${ }^{1}$ \\ Universitas Islam Negeri Sumatera Utara ${ }^{2}$ \\ Universitas Islam Negeri Sumatera Utara ${ }^{3}$ \\ Email: andanapohan@iainlangsa.ac.id
}

\begin{abstract}
ABSTRAK
Penelitian bertujuan untuk mengetahui (1) program apa saja yang dilaksanakan Penyuluh KB, (2) bagaimana metode yang digunakan dalam pelaksanaan program $K B$, (3) hambatan yang dihadapi penyuluh dan yang terakhir adalah untuk mengetahui faktor yang mendukung pelaksanaan program KB. Metode penelitian yang digunakan adalah metode penelitian kualitatif dengan teknik analisa data yang dilakukan dengan merujuk kepada teknik analisa data model Miles dan Huberman yaitu: Reduksi data, display data, dan penarikan kesimpulan. Informan penelitian adalah empat orang penyuluh KB Kecamatan Kotapinang. Hasil penelitian menemukan bahwa Program yang dilaksanakan Penyuluh KB adalah program KB dengan beberapa sub program pendukung. Sementara metode yang digunakan adalah metode langsung dan metode tidak langsung. Beberapa faktor menjadi penghambat dalam pelaksanaan Program KB antara lain: Faktor masyarakat yang kurang merespon, budaya, rendahnya pendidikan, dan geografis. Sementara faktor pendukung pelaksanaan Program KB yaitu faktor internal dari penyuluh, sementara faktor eksternal yaitu dukungan pemerintah, masyarakat, maupun swasta.
\end{abstract}

Kata Kunci: Penyuluh, KB

\begin{abstract}
The purpose of this study was to determine (1) what kind of program conducted by KB Counsellor (2) How is the method used in conducting KB programs (3) what kind of the oobstacles faced by counsellor and (4) what kind of supporting factor in conducting KB program. Research method used in this study was qualitative research by using data analysis Miles and Huberman model namely: data reduction, data displaying, summarising. Research informant is four KB counsellors of sub-district of Kotapinang. The study result showed that program conducted by KB counsellor is $K B$ program that is combined with some of supported sub-program. In addition, method used was directing and in directing method. Some of obstacle factors faced in conducting KB program are community factors, cultures, level of education, people mindset, and geographic factor. On the other hand, there are some supported programs namely external factor such as level of education and internal factor such as counselor itself.
\end{abstract}

Keywords: Counselors, $\mathrm{KB}$ 


\section{PENDAHULUAN}

Manusia yang merupakan seorang individu yang terkecil tentu tidak dapat hidup secara sendiri-sendiri di dunia ini, oleh sebab itu perlu adanya sebuah naungan kelompok untuk dapat menghadapi segala tantangan, rintangan masalah yang datang menghadang hidup. Salah satu kelompok naungan terkecil itu adalah keluarga. Keluarga merupakan salah satu unit yang paling terkecil yang terdiri atas orang tua dan anak, harus mampu memberikan kontribusi yang sangat besar bagi kemajuan dan kesejahteraan keluarga itu sendiri, masyarakat, bangsa dan negara juga agama. Namun sebaliknya juga keluarga juga bisa menjadi sebuah akar masalah atas segala kerusakan, hambatan-hambatan yang ada pada masyarakat, bangsa dan negara juga bagi agama itu sendiri.

Salah satu masalah mendasar dan menjadi tolok ukur bagi kemajuan sebuah bangsa ialah masalah kesejahteraan sosial masyarakat. Indonesia merupakan salah satu bangsa yang besar baik dari segi wilayah, sumber daya alam, budaya, agama, bahasa, dan juga yang tidak kalah penting ialah besar dalam jumlah penduduk.

Pada tanggal 31 oktober 2011 lalu PBB memproyeksikan bahwa penduduk dunia telah mencapai 7 miliar jiwa. Indonesia merupakan negara kontributor keempat penduduk setelah China, India, dan Amerika (Jumlah Penduduk Dunia 7 Miliar Jiwa dalam http://www.voaindonesia.com ). Oleh sebab itu maka pemerintah sudah sejak lama menggalakkan program Keluarga Berencana $(\mathrm{KB})$ untuk mengantisipasi laju pertumbuhan penduduk yang semakin besar itu. Namun era otonomi daerah terlihat program KB terasa melemah, berdasar pada data sensus penduduk tahun 2010. Jumlah penduduk mencapai 237,6 juta jiwa, melampaui angka proyeksi yang hanya 234 juta jiwa. Laju pertumbuhan penduduk naik dari 1,47\% per tahun antara 19902000 menjadi 1,49\% per tahun pada periode 2000-2010 (KKB, 2011). Ini berarti terjadi pertambahan jumlah penduduk sebesar sekitar $0,02 \%$ atau jika diangkakan mencapai 3 - 4 juta jiwa setiap tahun. Ini jumlah yang sangat banyak dan akan memberikan implikasi terhadap ketersediaan berbagai kebutuhan hidup, yang pada gilirannya akan memberikan pengaruh terhadap kehidupan bermasyarakat, berbangsa dan beragama. 
Dengan laju pertumbuhan penduduk $1,49 \%$ per tahun, jumlah penduduk Indonesia pada 45-50 tahun yang akan datang diperkirakan akan berlipat ganda menjadi 474 juta jiwa dan dalam 100 tahun yang akan datang menjadi hampir 1 miliar jiwa (KKB, 2011). Jumlah penduduk sebesar ini menjadi ancaman yang luar biasa bagi ketersediaan pangan. Selain itu, pemerintah juga akan mengalami kesulitan besar dalam memenuhi kebutuhan dasar penduduk seperti pangan, lapangan kerja, infrastruktur, pelayanan kesehatan, dan pendidikan.

Penduduk sebagai modal dasar dan faktor dominan pembangunan harus menjadi titik sentral dalam pembangunan berkelanjutan, apabila diimbangi dengan kualitas yang baik. Gejala tersebut sekarang ini sudah terjadi di depan mata, mulai dari Global Warming, pencemaran udara, perusakan lingkungan yang ujungnya banjir dimana-mana, longsor, meletusnya gunung merapi, tsunami, serta gizi buruk, bahkan pelecehan TKI, maraknya begal, aliran-aliran agama seperti ISIS, NII, dll. Ini semua adalah bencana yang akar masalahnya berawal dan bermula dari persoalan hulu yakni penduduk yang semakin banyak, tetapi kualitas dan kesejahteraannya rendah.

Hal tersebut sejalan dengan hasil penilaian UNDP, hasil perhitungan Indeks Pembangunan Manusia (IPM) Indonesia tahun 2011 memperlihatkan angka yang mengejutkan dimana angka tersebut menurun dari tahun 2010, yakni berada pada posisi 124 dari 187 negara di dunia, pada tahun 2010 berada pada posisi 108 dari 169 negara (IPM Indonesia dalam http://www.srie.org).

Oleh sebab itu tidak ada cara lain untuk mengurangi laju pertumbuhan penduduk yaitu terus menggalakkan program $\mathrm{KB}$, namun yang lebih mengejutkan lagi baru-baru ini BKKBN mengaku telah gagal menurunkan angka kelahiran (total fertile rate) sepanjang 2012. Hingga akhir tahun penurunan fertilitas tetap pada angka 2,6 dari target 2,1\%, hal tersebut disampaikan oleh Deputi Keluarga Sejahtera dan Pemberdayaan Keluarga BKKBN, Sudibyo Alimoeso saat refleksi awal tahun program kependudukan dan KB di Jakarta (Harian Waspada, 15 Januari 2013).

Kabupaten Labuhanbatu Selatan juga jauh lebih mengejutkan lagi dari hasil pendataan tahun 2012 oleh Badan Keluarga Berencana Pemberdayaan Perempuan dan Perlindungan Anak (BKBPP dan PA) diketahui jumlah penduduk Kabupaten 
Labuhanbatu Selatan mencapai 285.063 jiwa terdiri dari laki-laki (142.346) jiwa dan perempuan (142.717) jiwa dengan jumlah kelahiran (Total Ferteliti Rate) yaitu $4,31 \%$ dan laju pertumbuhan penduduk yaitu 2,38 \% jauh lebih besar dari pertumbuhan penduduk skala nasional (BKBPPPA, 2012).

Penyuluh KB merupakan ujung tombak dalam menyukseskan program KB sehingga laju pertumbuhan penduduk tidak semakin cepat dan bertambah. Penyuluh KB sebagai garda paling depan, yang langsung bersentuhan dengan masyarakat. Tentu telah bekerja secara maksimal, namun kenyataannya hasil berkata lain dan belum sesuai dengan hasil yang diharapkan. Hal inilah menjadi dasar penelitian ini dilakukan, apa sebenarnya yang terjadi pada Penyuluh KB di BKBPP dan PA Kabupaten Labuhanbatu Selatan terkhusus di Kecamatan Kotapinang.

\section{METODE PENELITIAN}

Jenis penelitian ini adalah penelitian deskriftif kualitatif (Moleong, 2006). Penelitian ini dilaksanakan di kantor BKBPP dan PA Kabupaten Labuhanbatu Selatan yang dilakukan mulai dari bulan Januari-Mei 2013. Informan dalam penelitian ini adalah Penyuluh KB Kecamatan Kotapinang sebanyak empat orang, masyarakat dan pimpinan lembaga dalam hal ini kepala BKBPP dan PA Kabupaten Labuhanbatu Selatan.

Teknik pengumpulan data yang dilakukan adalah observasi, wawancara, dan dokumentasi. Untuk memeriksa keabsahan data yang telah didapatkan dan agar tidak terjadi informasi yang salah atau tidak sesuai dengan konteks yang diberikan informan maka dilakukan pemeriksaan keabsahan data melalui: memperpanjang waktu penelitian di lapangan, persistance of resistance, melakukan triangulasi yaitu triangulasi dengan teknik yang banyak, analisis kasus negatif, dan menggunakan referensi yang tepat. Teknik analisa data yang dilakukan dengan merujuk kepada teknik analisis data model Miles dan Huberman yaitu: reduksi data, display data, dan penarikan kesimpulan (Yusuf, 2013). 


\section{HASIL PENELITIAN DAN PEMBAHASAN}

\section{Program Penyuluh KB}

Program-program yang dilakukan oleh penyuluh merupakan program yang berdadarkan instruksi dari BKKBN pusat, adapun program itu adalah program KB yang ada didalamnya sub program pendukung yaitu: Bina Keluarga Balita (BKB), Bina Keluarga Remaja (BKR), Bina Keluarga Lansia (BKL), dan Usaha Peningkatan Pendapatan Keluarga Sejahtera (UPPKS), yang merupakan suatu sistem yang saling berhubungan satu dengan lainnya.

Program-program yang dilaksanakan penyuluh KB tentunya berdasarkan kebutuhan masayarakat (need assessment) calon akseptor KB. Program yang dilaksanakan sesuai dengan kebutuhan, untuk pasangan usia subur yang baru mempunyai anak tentunya programnya adalah BKB. Untuk keluarga yang mempunyai anak remaja program yang diberikan adalah BKR, begitulah seterusnya. Prinsip-prinsip pelayanan KB tersebut berkenaan dengan kondisi masyarakat, program pelayanan, serta tujuan dan pelaksanaan layanan, yang mengacu pada

pelayanan yang efektif dan efisien untuk kehidupan yang efektif sehari-hari (KES), cerdas dan berkarakter (Prayitno, dkk. 2013: 8).

\section{Metode dan Jenis Layanan yang Diberikan}

Secara metode penyuluh melaksanakan dua metode yaitu metode langsung dan tidak langsung. Metode langsung yang digunakan adalah memanfaatkan momentum perkumpulan masyarakat seperti perwiritan, P.KK, Posyandu, ceramah, wawancara (face to face), dialog dan tanya jawab. Metode tidak langsung yang dilakukan adalah menyebar brosur, melalui papan reklame, pamplet, reklame surat kabar, serta melalui media televisi dan internet.

Berdasarkan metode yang dilakukan penyuluh $\mathrm{KB}$, termasuk ke dalam jenis layanan dan kegiatan pendukung BK antara lain: Layanan orientasi yang membantu masyarakat mengetahui gambaran tentang keluarga sejahtera. Layanan informasi memberikan informasi mengenai jenis-jenis KB yang dilakukan. Layanan konsultasi merupakan konsultasi mengenai keadaan akseptor KB yang merasa penting untuk dikonsultasikan. Sedangkan kegiatan pendukung yang dilakukan oleh penyuluh $\mathrm{KB}$ 
antara lain: Himpunan data, yaitu menghimpun data masyarakat yang relevan dengan perkembangan masyarakat, yang diselenggarakan berkelanjutan, sistematis, komprehensif, terpadu dan bersifat rahasia. Kunjungan rumah yaitu para penyuluh datang door to door ke masyarakat untuk mensosialisasikan program KB untuk kesejahteraan masyarakat (ABKIN, 2013).

\section{Hambatan dalam Pelaksanaan Program}

Adapun hambatan-hambatan yang menjadi faktor penghambat pelaksanaan program antara lain: Faktor dari masyarakat itu sendiri yang kurang merespon, Faktor budaya yang masih melekat kuat di sebagian masyarakat, Faktor rendahnya pendidikan masyarakat, Faktor pola pikir masyarakat yang kurang memahami dan langsung menjustifikasi bahwa KB itu haram, Faktor georafis daerah yang masih sulit untuk dijangkau.

Itulah sebenarnya yang harus dipahami oleh penyuluh $\mathrm{KB}$, maka seorang penyuluh dituntut untuk tidak mudah putus asa, karena penyuluh KB melaksanakan tugas yang mulia, tugas negara untuk kesejahteraan masyrakat juga tentunya. Sebagaimana syarat-syarat penyuluh atau konselor Islami harus memiliki sifat-sifat kepribadian yang akan mendukung dalam misi dan tugas penyuluhan KB tersebut, yaitu: penuh pengertian, simpati, ramah, memiliki rasa humor, emosi yang stabil, sabar, objektif, ikhlas, bijaksana, jujur, berpandangan luas, baik hati, menyenangkan, tanggap dengan situasi sosial, dan sikap tenang (Lubis, 2007: 41).

Dalam hal ini memang seharusnya penyuluh tidak mudah putus asa, karena tentu masih ada jalan lain, agar masyarakat mau mengikuti program KB yang disampaikan, penyuluh KB harus tetap ikhlas, sebagaimana firman Allah Swt. Q. S. Al-Zalzalah/99: 7-8

Artinya: "Barangsiapa yang mengerjakan kebaikan seberat dzarrahpun, niscaya Dia akan melihat (balasan)nya. Dan Barangsiapa yang mengerjakan kejahatan sebesar dzarrahpun, niscaya Dia akan melihat (balasan)nya pula”.

Ayat diatas merupakan motivasi bagi Penyuluh KB agar tidak mudah putus asa, ikhlas dalam berbuat, karena kebaikan yang dilakukan sebesar dzarrahpun Allah 
akan membalasnya, Penyuluh KB tidak perlu khawatir ketika masyarakat menolak masih ada Allah yang menilai perbuatan baik itu.

Sikap tersebut perlu diperhatikan dan menjadi patokan bagi Penyuluh KB di lapangan adalah sikap sabar, sebagaimana firman Allah Swt (Q. S. Ali-Imran/3: 159)

Artinya: "Maka disebabkan rahmat dari Allah-lah kamu berlaku lemah lembut terhadap mereka. Sekiranya kamu bersikap keras lagi berhati kasar, tentulah mereka menjauhkan diri dari sekelilingmu. karena itu ma'afkanlah mereka, mohonkanlah ampun bagi mereka, dan bermusyawarahlah dengan mereka dalam urusan itu. kemudian apabila kamu telah membulatkan tekad, Maka bertawakkallah kepada Allah. Sesungguhnya Allah menyukai orang-orang yang bertawakkal kepada-Nya".

\section{Faktor Pendukung dalam Pelaksanaan Program}

Adapun faktor-faktor pendukung pelaksanaan program oleh penyuluh antara lain: Faktor internal dari dalam diri penyuluh sendiri, yaitu faktor pendidikan, motivasi altruistik, semangat yang tinggi. Faktor eksternal merupakan faktor-faktor yang mendukung dari luar diri penyuluh antara lain: dukungan dari para aparat pemerintah seperti Kepala Desa, Sekretaris Desa, Ibu PKK, perusahaan swasta, kemudian obat-obatan yang mendukung program yang disediakan oleh pemerintah. Faktor dari luar diri penyuluh yang sangat membantu itulah yang dinamakan dengan dukungan sistem. Menyadari bahwa penyuluh tidak akan mampu bekerja secara sendiri tanpa bantuan dari berbagai pihak dalam mensosialisasikan, melaksanakan, maupun mengevaluasi program.

\section{KESIMPULAN}

Berdasarkan hasil penelitian dan pembahasan, maka dapat disimpulkan sbb:

1. Menjadi seorang Penyuluh KB merupakan sebuah tugas yang tidak mudah untuk dijalankan oleh setiap orang. Program KB merupakan sebuah program pokok yang didukung oleh beberapa sub programnya yaitu Bina Keluarga Balita (BKB), Bina Keluarga Remaja (BKR), Bina Keluarga Lansia (BKL) dan Usaha Peningkatan Pendapatan Keluarga Sejahtera (UPPKS). 
2. Program-program itu disampaikan dengan metode yang baik pula oleh para Penyuluh KB yaitu menggunakan metode langsung dan tidak langsung. Metode langsung mencakup wawancara, ceramah, diskusi, dialog dan door to door. Sedangkan metode tidak langsung yang dipakai adalah melalui brosur, pamflet, reklame, iklan media cetak radio maupun televisi.

3. Dalam melaksanakan tugasnya penyuluh tentu tidak terlepas dari masalah dan hambatan yang dihadapi, masalah-masalah seperti berhadapan langsung pada calon akseptor KB, yaitu ada yang menolak karena pengaruh pendidikan, agama, dan juga budaya fanatik yang masih melekat di masyarakat.

4. Namun semua masalah itu bukanlah tanpa faktor dukungan bagi Penyuluh KB, dukungan itu berasal dari internal penyuluh dan juga dari faktor eksternal penyuluh itu sendiri. Dukungan dari kedua faktor inilah yang terus memberikan eksistensi bagi kelangsungan program KB di Kecamatan Kotapinang.

5. Keberhasilan Penyuluh KB di Kecamatan Kotapinang bukanlah tanpa ukuran, ini dibuktikan dengan temuan umum pada penelitian ini adalah terjadi peningkatan rata-rata 61 orang setiap bulan peserta $\mathrm{KB}$ aktif di daerah tersebut.

\section{DAFTAR RUJUKAN}

ABKIN. 2013. Panduan Umum Pelayanan Bimbingan dan Konseling. Jakarta.

BKBPPA Labusel. 2012. Data Program Kependudukan dan KB Kabupaten Labuhanbatu Selatan. Kotapinang: BKBPPPA.

Lahmuddin, Lubis. 2007. Bimbingan Konseling Islami. Jakarta: Hijri Pustaka Utama.

Moleong, Lexy. J. 2006. Metodologi Penelitian Kualitatif. Bandung: Remaja Rosda Karya.

Prayitno, dkk. 2013. Pembelajaran Melalui Pelayanan BK di Satuan Pendidikan. Jakarta: ABKIN.

Yusuf, A Muri. 2013. Metode Penelitian Kualitatif, Kuantitatif, dan Gabungan. Padang: UNP Press.

TP. 2013. The Holy Qur'an Al Fatih. Jakarta: Al Fatih.

TP. 2013. Jumlah Penduduk Dunia 7 Miliar Jiwa dalam http://www.voaindonesia.com.

TP. 2013. IPM Indonesia dalam http://www.srie.org. 
JUANG: Jurnal Wahana Konseling (Vol. 1, No. 2, September 2018)

TP. 2013. 35 Tahun Lagi Penduduk Indonesia Diperkirakan 500 Juta. Medan: Harian Waspada, 15 Januari.

TP. 2011. Laju Pertumbuhan Penduduk Indonesia yang Tidak Terkendali. Jakarta: KKB. 